\title{
CARACTERIZAÇÃO DO RESÍDUO DE PÓ DE PEDRA ORNAMENTAL ADICIONADO À ARGAMASSA EM SUBSTITUIÇÃO PARCIAL AO CIMENTO
}

\author{
A. K. C. NOBREGA ${ }^{1}$, M. V. V. A. de $\mathrm{SA}^{2}$, R. A. AMARAL ${ }^{3}$, S. E. GOIS ${ }^{4}$, G. M. \\ DANTAS ${ }^{5}$ \\ ${ }^{1}$ Universidade Federal Rural do Semi-Árido, Departamento de Engenharia Civil \\ ${ }^{2}$ Universidade Federal do Rio Grande do Norte, Departamento de Engenharia Civil \\ ${ }^{3}$ Universidade Federal do Rio Grande do Norte, Departamento de Engenharia Civil \\ ${ }^{4}$ Universidade Federal do Rio Grande do Norte, Departamento de Engenharia Civil \\ ${ }^{5}$ Universidade Federal do Rio Grande do Norte, Departamento de Engenharia Civil \\ E-mail para contato: akcn123@ hotmail.com
}

\begin{abstract}
RESUMO - O crescimento da população elevou o mercado da construção civil, aumentando o consumo de materiais. Visando o aproveitamento sustentável de resíduos minerais, desenvolveu-se uma argamassa substituindo parte do cimento por resíduo produzido em marmorarias após o polimento de peças em mármore e granito. Estudou-se o traço de regularização 1:3 (cimento:areia fina), com adição de 5\%, 10\%, 20\% e 50\% de substituição do cimento Portland pelo resíduo de pó de pedra. Foram realizados ensaios de caracterização dos materiais e da argamassa: absorção, resistência mecânica, módulo de elasticidade e arrancamento. $\mathrm{O}$ ensaio de absorção apresentou baixa variação quando comparado à argamassa com menor adição de resíduo. A análise da resistência mecânica à compressão com adição em relação à argamassa base foi positiva. A redução dos valores do módulo de elasticidade significa uma melhor capacidade de deformação da argamassa. $\mathrm{O}$ aumento da adição de resíduo fragiliza superficialmente a argamassa após 28 dias de sua aplicação, mas aumenta a aderência do revestimento ao chapisco, isso foi constatado no ensaio de arrancamento. Pode-se concluir que a substituição parcial do cimento Portland pelo resíduo de pó de pedra ornamental é viável e possível.
\end{abstract}

\section{INTRODUÇÃO}

A construção civil é umas das áreas que atualmente mais tem gerado demanda por uso de produtos e matérias primas, onde sua extração e manejo geram impactos ambientais, tais como: erosão, assoreamento de corpos hídricos, contaminação de rlençóis freáticos e mananciais, entre outros. Com isso, as indústrias estão tomando medidas mais eficazes acerca da diminuição do uso de recursos naturais, buscando o uso de novos materiais que apresentem maior eficiência e proporcione um descarte e reaproveitamento sustentável dos resíduos gerados pela sua atividade (Ângulo et al., 2001).

O Brasil é o quarto maior produtor de rochas ornamentais e também de rochas processadas. Os processos de corte, serragem e polimento geram uma lama abrasiva, 
contendo grão finos, capaz de levar rios, lagos, córregos e até reservatórios naturais de água a altos níveis de contaminação (Simsek apud Manhães \& Holanda, 2009). Esse resíduo possui grande potencial para adição a matrizes cimentíceas, pois possui elevada estabilidade e resistência à abrasão (Apolinário et al., 2013). Visando conferir uma destinação final adequada a este abundante resíduo, seu emprego como matéria-prima alternativa, sobretudo no âmbito dos materiais de construção, vem sendo investigado por diversos pesquisadores. Sabe-se que a composição química do resíduo é um indicador de sua compatibilidade com as matrizes cimentíceas, e sua forma granular com elevada finura o torna um material com bom potencial de utilização como adição mineral em concretos e argamassas, podendo agir como fíller (Gonçalves, 2000; Menezes et al., 2009; Aruntas et al., 2010; Corinaldesi et al., 2010).

No entanto, avaliou-se a incorporação do resíduo de pó de pedra na argamassa de revestimento, que é um dos produtos de elevada produção e consumo de cimento Portland na construção civil. O traço 1:3 é considerado um traço usual e resistente, mas é comum apresentar fissuras ao longo da parede devido ao percentual elevado de cimento na formulação. Para analise da interação entre resíduo e demais componentes da argamassa foram analisadas as substituições de frações de cimento Portland pelas respectivas porcentagens de pó de pedra ornamental em 5\%, $10 \%$ e $20 \%$ e $50 \%$ objetivando manter ou melhorar as propriedades da argamassa padrão com esse traço, reduzindo a quantidade de cimento na formulação inicial e as patologias apresentadas.

\section{MATERIAIS E MÉTODOS}

\subsubsection{Materiais de partida}

Utilizou-se o cimento CPII-F 32 (Cimento Portland composto com filler) da marca CIMPOR. Suas propriedades atendem desde estruturas em concreto armado até argamassas de assentamento e revestimento, concreto massa e concreto para pavimentos. O CP II F-32 tem adição de fíler calcário, em teor entre 6 e $10 \%$.

O agregado miúdo utilizado é oriundo de leito de rio localizado na região metropolitana do Rio Grande do Norte e comercializado na grande natal. Apresenta granulometria fina, com grãos regulares e módulo de finura (MF) 2,30.

O resíduo produzido em marmorarias da região Potiguar foi coletado em estado bruto, e posteriormente submetido à secagem em estufa por 24 horas e subsequente moagem em moinho de bolas por 6 horas. Esse processo foi realizado a fim de diminuir mais ainda a granulometria do pó de pedra e assim favorecer sua interação com a matriz cimentícia.

Usou-se na mistura da argamassa água proveniente da rede de abastecimento local. 


\subsubsection{Ensaios}

A análise química do resíduo de pó de pedra ornamental, tabela 1 , foi realizado através da técnica de Fluorescência de Raios-X utilizando o equipamento EDX-720 da marca Shimadzu. Apresentou uma porcentagem predominante de sílica e óxido de cálcio em sua composição, componentes fundamentais do cimento Portland.

Tabela 1 - Resultado do ensaio de EDX para resíduo de pó de pedra ornamental

\begin{tabular}{|c|c|}
\hline Componentes & Porcentagem (\%) \\
\hline $\mathrm{SiO} 2$ & $43.627 \%$ \\
\hline $\mathrm{CaO}$ & $26.039 \%$ \\
\hline $\mathrm{Al} 2 \mathrm{O} 3$ & $12.183 \%$ \\
\hline $\mathrm{MgO}$ & $7.916 \%$ \\
\hline $\mathrm{Fe} 2 \mathrm{O} 3$ & $4.653 \%$ \\
\hline $\mathrm{K} 2 \mathrm{O}$ & $3.268 \%$ \\
\hline $\mathrm{SO} 3$ & $2.142 \%$ \\
\hline $\mathrm{MnO}$ & $0.080 \%$ \\
\hline $\mathrm{Tm} 2 \mathrm{O} 3$ & $0.059 \%$ \\
\hline $\mathrm{ReO} 2$ & $0.031 \%$ \\
\hline $\mathrm{ZnO}$ & $0.002 \%$ \\
\hline
\end{tabular}

O resíduo de pó de pedra ornamental foi submetido à análise de difração de raios-X (DRX) através do equipamento XRD-6000 da marca Shimadzu.

A formulação da argamassa foi baseada no traço 1:3 (cimento: areia fina), com substituição parcial do cimento Portland pelo resíduo de pó de pedra ornamental nas porcentagens $5 \%, 10 \%, 20 \%$ e $50 \%$, de acordo com a tabela 2 .

Tabela 2 - Composição da argamassa

\begin{tabular}{|c|c|c|}
\hline Argamassa & $\begin{array}{c}\text { Traço em volume } \\
\text { (cimento:areia) }\end{array}$ & Índice de consistência (cm) \\
\hline Referência & $1: 3$ & 25,0 \\
\hline $5 \%$ & $0,95: 0,05: 3$ & 26,0 \\
\hline $10 \%$ & $0,90: 0,10: 3$ & 25,5 \\
\hline $20 \%$ & $0,80: 0,20: 3$ & 25,5 \\
\hline $50 \%$ & $0,50: 0,50: 3$ & 25,0 \\
\hline
\end{tabular}

No processo de mistura dos componentes foi empregado o Misturador mecânico (argamassadeira) de eixo vertical com capacidade de 5 L, da marca PAVITEST C 3010146-380. De acordo com os procedimentos da NBR 13276. 
O ensaio de índice de consistência foi realizado na mesa flow table padrão conforme a norma NBR 7215, uma balança com precisão de $0,1 \mathrm{~g}$. e paquímetro, de acordo com a norma NBR 13276,2002.

Para o ensaio de absorção de água por capilaridade, foram moldados corpos de prova prismáticos, três para cada adição, e colocados com uma das extremidades em contato com uma lâmina d'agua de $5 \mathrm{~cm}$, de acordo com a norma NBR 15259, 2005. Esse ensaio mede a quantidade de água absorvida pelo corpo de prova no decorrer do tempo.

Para os ensaios de resistência mecânica usou-se uma prensa universal da shimadzu. Com carga de acordo com a norma NBR 13279, 2005. Os corpos de prova prismáticos foram curados por 7 e 28 dias.

Para o ensaios de módulo de elasticidade dinâmico, usou-se o equipamento TICO com emissão de ondas ultrassônicas de pulso elétrico de baixa frequência, seguindo a norma NBR 15630, 2008.

O ensaio de arrancamento das placas do revestimento foi realizado de acordo com a NBR 13528. A cura do revestimento ocorreu por 28 dias e para cada porcentagem de adição foram analisadas 5 amostras.

\section{RESULTADOS}

Observou-se na caracterização do pó de pedra através da análise química do material a presença predominante da sílica e do $\mathrm{CaO}$, um dos componentes principais do cimento Portand. No entanto, o DRX do resíduo apresentou aspectos cristalinos e picos de Sílica $\left(\mathrm{SiO}_{2}\right)$ em sua maioria. Caracterizando que o resíduo apresenta a sílica na forma cristalina e menos reativa. Isso reduz a ideia de uma atividade pozolânica desse material mineral.

A argamassa apresentou consistência adequada aos valores normativos, com quase nenhuma variação na quantidade de água adicionada para cada porcentagem de adição. De acordo com a opinião do pedreiro experiente, a medida que aumenta a adição do resíduo de pó de pedra e diminui a quantidade de cimento na argamassa, esta apresenta uma melhora na trabalhabilidade e aderência.

O ensaio de absorção após 28 dias de cura apresentou pequeno aumento com a adição do resíduo. Os resultados após 10 min e 90 min de contato com a água apresentaram-se constante com aumento após $20 \%$ de adição do resíduo. A figura 1 apresenta os resultados obtidos após a adição do resíduo. 
Absorção (\%) - 28 dias

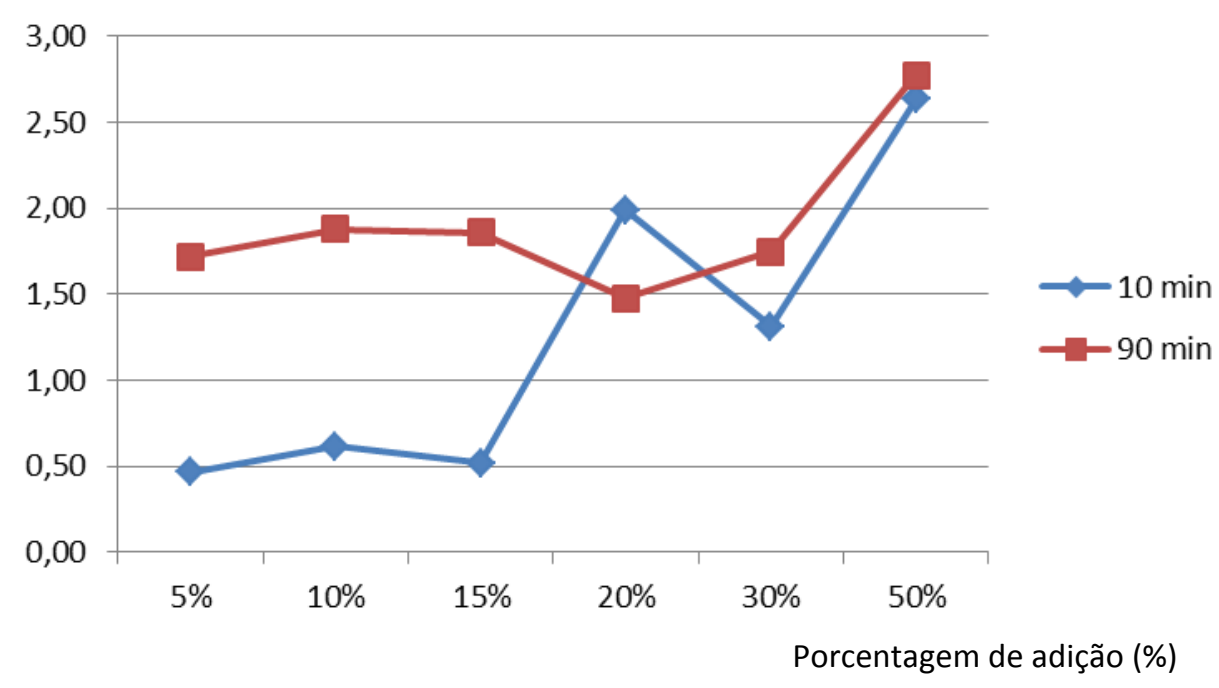

Figura 1 - Resultados do ensaio de absorção do corpo de prova de argamassa após 10 min e 90 min de contato com a água

Os resultados de resistência mecânica, figura 2, apresentaram uma diminuição considerável após $15 \%$ de adição do pó de pedra. No entanto após $15 \%$ de adição houve um ganho na resistência mecânica da argamassa melhor que o corpo de prova de referência. $\mathrm{O}$ corpo de prova foi mantido em cura úmida por 28 dias.

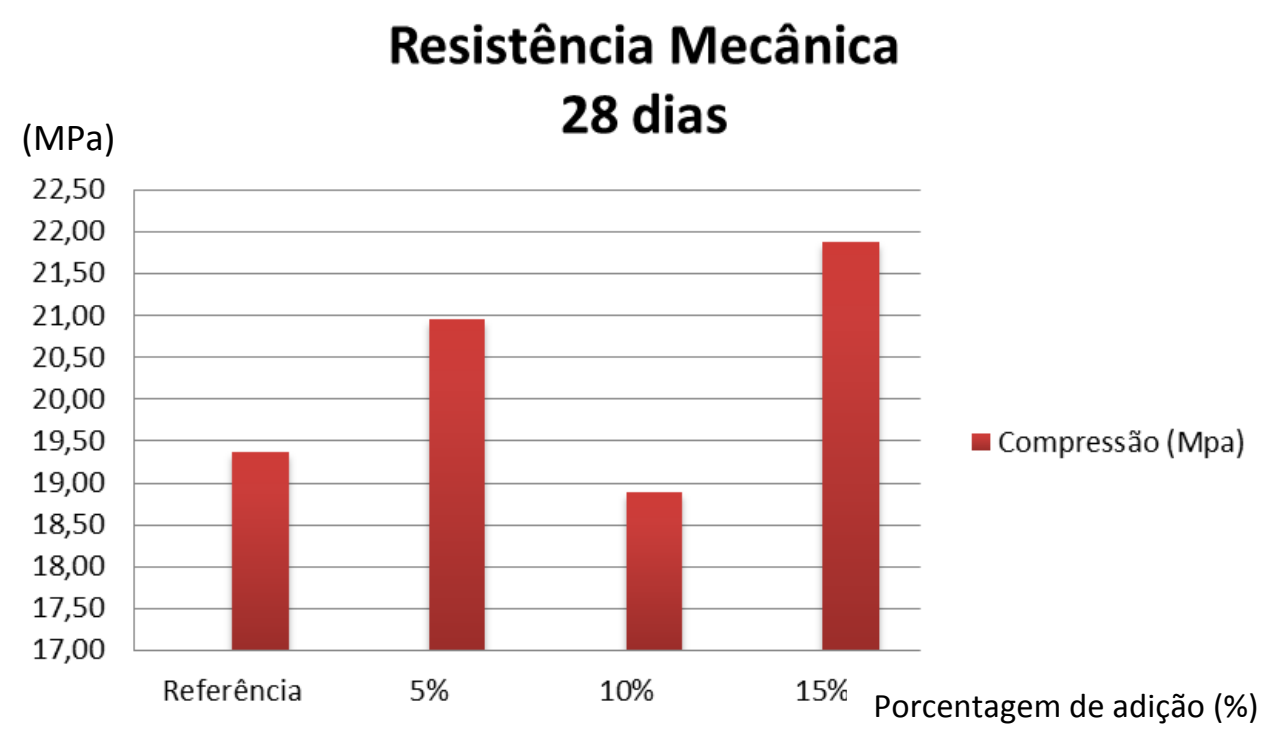

Figura 2 - Resistência mecânica da argamassa de referência e com adição de até $15 \%$ do resíduo de pó de pedra ornamental

Os resultados do ensaio de módulo de elasticidade dos corpos de prova após 28 dias de cura úmida, figura 3, apresentaram valores positivos, pois houve diminuição gradual com o aumento da porcentagem do resíduo na formulação da argamassa. Essa diminuição contribui para a redução de fissuras ao longo da superfície do revestimento, 
pois a argamassa tende a ter uma maior deformação elástica quando aplicada uma dada tensão.

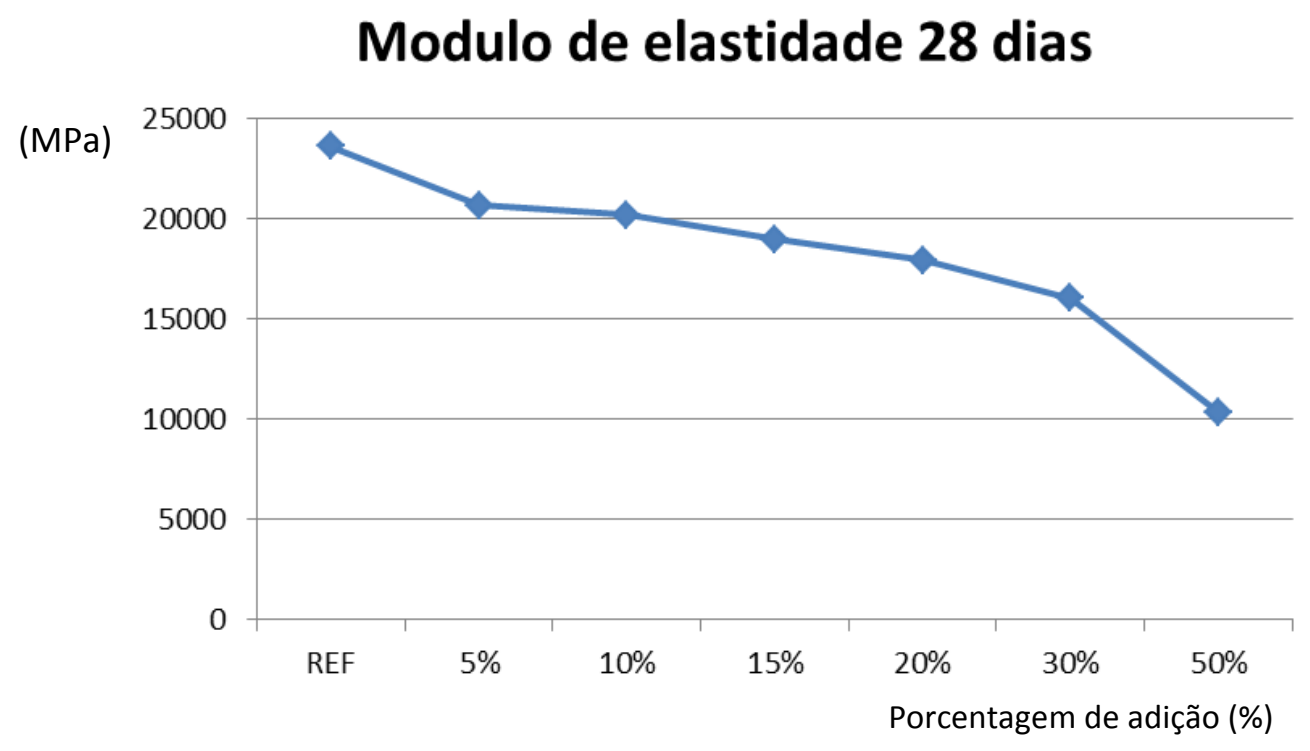

Figura 3 - Resultados de módulo de elasticidade da argamassa de referência e com adição do resíduo de pó de pedra

O ensaio de arrancamento após 28 dias, figura 4, apresentou uma diminuição gradual após a adição de $20 \%$ do resíduo na argamassa. Essa redução ocorreu devido a um aumento na fragilidade superficial do revestimento. No entanto, houve um aumento na aderência da argamassa, pois apenas a parte superficial do revestimento ficou aderido a placa do ensaio.

\section{Resistência a tração}

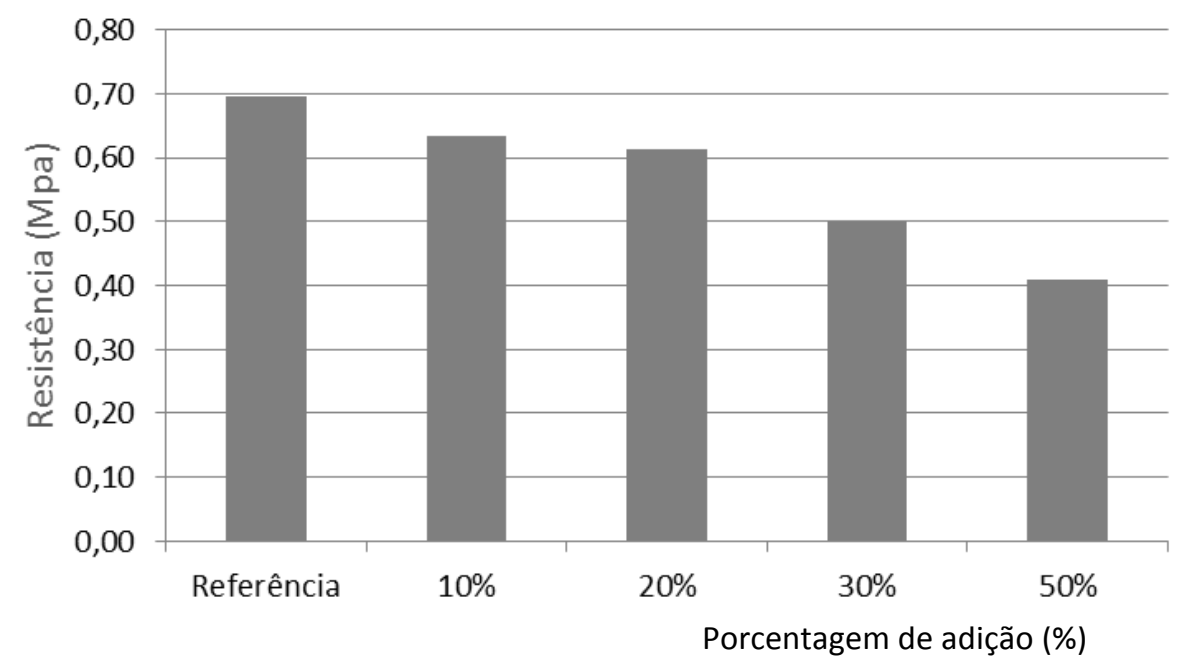

Figura 4 - Resultado de aderência da argamassa de referência e com adição do resíduo 


\section{CONCLUSÃO}

De acordo com a análise dos resultados obtidos, conclui-se que é possível a substituição parcial do cimento Portland na argamassa de regularização, com traço 1:3. A trabalhabilidade da argamassa melhora a medida que se aumenta a adição do resíduo e diminui a quantidade de cimento na formulação. A absorção aumentou após a adição de $20 \%$ do resíduo de pó de pedra e a resistência mecânica dos corpos de prova tiveram uma redução nos valores após $15 \%$ de adição do resíduo na formulação. No entanto, o módulo de elasticidade baixou, aumentando a capacidade da argamassa de resistir a deformação elástica quando submetida a uma dada tensão. Isso reduz a formação de fissuras ao longo do revestimento. A aderência superficial da argamassa diminuiu após $20 \%$ de adição do resíduo, mas a interface entre o revestimento e o chapisco se manteve resistente a tração aplicada.

Logo, pode-se concluir que a adição do resíduo de pó de pedra na argamassa em substituição parcial ao cimento Portland é viável e irá contribuir para uma destinação adequada desse material.

\section{REFERÊNCIAS}

ÂNGUlO, S. C.; ZORDAN, S. E.; JOHN, V. M.. Desenvolvimento sustentável e a reciclagem de resíduos na construção civil. Universidade de São Paulo, São Paulo, 2001.

MANHÃES \& HOLANDA. Caracterização e classificação de resíduo sólido "pó de rocha granítica" gerado na indústria de rochas ornamentais. Quimica Nova, v.31, n.6, p.1301-1304, 2009.

APOLINÁRIO, E.; MATTA, V.; RIBEIRO, D.. Efeito da adição do resíduo de corte de mármore e granito (RCMG) nas propriedades das argamassas de revestimento. Congresso Brasileiro de Engenharia e Ciência dos Materiais.2013.

GONÇALVES, J. P. Utilização do resíduo de corte de granito (RCG) como adição para produção de concretos. 2000, 135f. Dissertação (Mestrado em Engenharia Civil) Programa de Pós-Graduação em Engenharia Civil, Universidade Federal do Rio Grande do Sul, Porto Alegre.

ABNT NBR 13276. Argamassa para assentamento e revestimento de paredes e tetos - Preparo da mistura e determinação do índice de consistência. Comitê: ABNT/CB-018 Cimento, Concreto e Agregados. 3 Páginas, 2005.

ABNT NBR 15259. Argamassa para assentamento e revestimento de paredes e tetos - Determinação da absorção de água por capilaridade e do coeficiente de capilaridade. Comitê: ABNT/CB-018 Cimento, Concreto e Agregados. 3 Páginas, 2005.

ABNT NBR 13279. Argamassa para assentamento e revestimento de paredes e tetos - Determinação da resistência à tração na flexão e à compressão. Comitê: ABNT/CB-018 Cimento, Concreto e Agregados. 9 Páginas, 2005. 
ABNT NBR 15630. Argamassa para assentamento e revestimento de paredes e tetos - Determinação do módulo de elasticidade dinâmico através da propagação de onda ultra-sônica. Comitê: ABNT/CB-018 Cimento, Concreto e Agregados. 4 Páginas, 2008 .

- ABNT NBR 13528. Revestimento de paredes e tetos de argamassas inorgânicas - Determinação da resistência de aderência à tração. Comitê: ABNT/CB018 Cimento, Concreto e Agregados. 11 Páginas, 2010. 